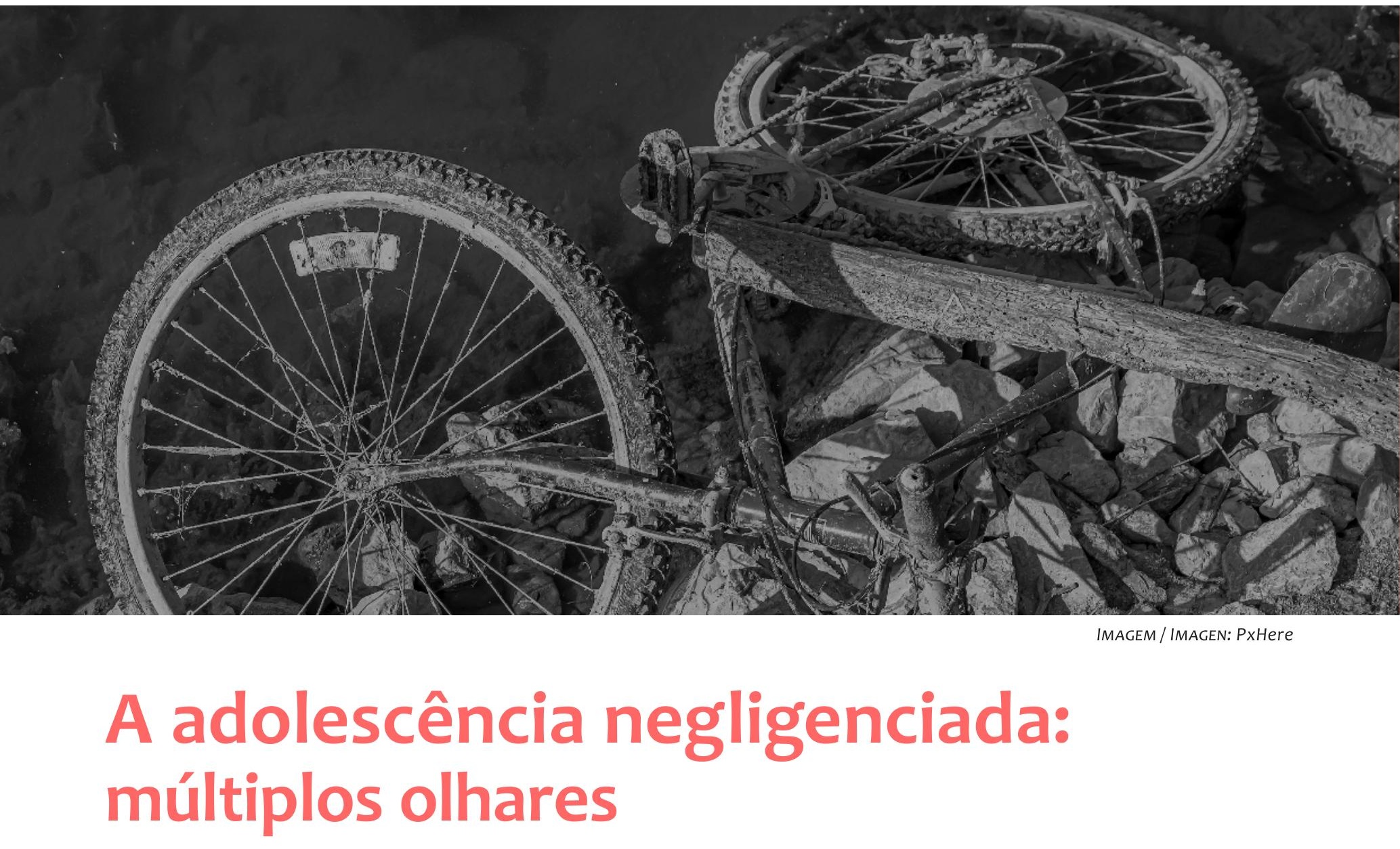

\title{
Joana Garcia
}

Universidade Federal do Rio de Janeiro, Escola de Serviço Social, Rio de Janeiro, Brasil https://orcid.org/0000-0002-7137-075X

\section{Ana Lucia Ferreira}

Universidade Federal do Rio de Janeiro, Departamento de Pediatria da Faculdade de Medicina, Rio de Janeiro, Brasil https://orcid.org/0000-0002-9672-7452

\section{Marta Rezende Cardoso}

Universidade Federal do Rio de Janeiro, Instituto de Psicologia, Departamento de Psicologia Clínica e Programa de Pós-Graduação em Teoria Psicanalítica, Rio de Janeiro, Brasil

https://orcid.org/0000-0003-1104-9830 
A questão da violência constitui um foco importante de nosso estudo interdisciplinar na procura de avançar na compreensão do que está em jogo na travessia da adolescência em sua dimensão relacional, tendo em vista a dimensão de alteridade que lhe é indissociável. É nessa trilha que abordaremos aspectos relativos à violência de caráter mais estrutural, que marca, de maneira inescapável, a experiência subjetiva e, como desdobramento dessa questão, nossa análise será dirigida a perspectivas de uma violência desestruturante, suscetível de atravessar a adolescência de distintas maneiras.

Daremos particular ênfase à presença da negligência, advinda do encontro com o outro, contemplando igualmente a violência cometida contra si mesmo, e isso sob distintas figuras. A negligência é uma expressão da violência frequentemente associada às crianças e suas famílias e pouco explorada na literatura brasileira em relação aos adolescentes e aos diversos atores responsáveis pela sua proteção. Sua ocorrência é associada a pessoas e instituições que deveriam representar e/ou oferecer suporte e proteção, mas que, por omissão, desinformação, discriminação, falta de recursos e/ou de prioridades, não o fazem. Postulamos que a proteção de qualquer pessoa adolescente é uma atribuição coletiva, que inclui, além dela mesma, um conjunto amplo de outras pessoas e instituições sociais com recursos diferenciados e funções desejavelmente complementares, não cabendo, portanto, uma leitura judicativa sobre um responsável isolado pela situação de negligência, especialmente quando se trata da figura materna.

Ao eleger a adolescência, enfatizamos a polissemia, tanto do ponto de vista das dimensões que a caracterizam como das formulações de distintos campos disciplinares sobre essa experiência de vida. Além dos aspectos epidemiológicos e psíquicos, buscam-se ressaltar as representações e práticas sociais voltadas para adolescentes segundo seu lugar social, definido pela classe, raça/cor, referência territorial, acesso à educação, saúde e profissionalização. A investigação dessas questões pode se enriquecer a partir de um olhar multidisciplinar. Nosso desafio é trabalhar essa questão em conjunto, sob o olhar de três áreas bem distintas, mas que nos parecem complementares: a Medicina, o Serviço Social e a Psicanálise.

Começaremos nossa reflexão apresentando elementos de caráter mais geral, buscando situar a adolescência no plano da subjetividade humana, tendo como base, inicialmente, o saber psicanalítico. Em seguida, uma contextualização ancorada nas ciências sociais e em elementos essenciais da área médica dá continuidade a nossa reflexão, marcando o caráter polissêmico da adolescência. Consideramos essencial delimitarmos as significações envolvidas na própria categoria de adolescência, particularmente o caráter múltiplo da condição juvenil na realidade brasileira por meio de uma apreciação e levantamento de dados de especial relevância dentro desse campo.

O artigo é construído com base na interlocução interdisciplinar com algumas referências conceituais consideradas centrais, entre elas, a adolescência e a negligência como uma das expressões da violência. $O$ debate apresentado dialoga com pesquisas prévias e dados extraídos de bases oficiais, além de ser ilustrado por um caso construído pelas autoras com base em suas experiências profissionais de pesquisa e intervenção com adolescentes e seus contextos sociais e familiares. 
A adolescência constitui uma experiência própria à existência humana que coloca uma demanda especial de trabalho ao psiquismo em razão das rupturas e transformações que traz ao sujeito. Da mesma ordem de relevância do plano do que se passa na vida infantil com seu poder de determinação nos destinos da vida psíquica, o adolescer deve ser considerado enquanto travessia, e não apenas como etapa cronológica. Através dela, tudo o que foi experimentado na infância, particularmente no que concerne a um plano inconsciente, será objeto de ressignificação. A adolescência produz forte ressonância psíquica das mudanças relativas ao advento da puberdade, estas tendo lugar no corpo biológico. No caso da adolescência, do ponto de vista da esfera psíquica, estamos situados num registro, radicalmente distinto desse, posto que movido por outra força, a força da pulsão, que se distingue da força do instinto, base do registro biológico. Como ressalta Laplanche (2001), ainda que os entrecruzamentos entre esses registros sejam fundamentais, a relação entre eles pode ser representada sob a figura de uma tangente, a partir da qual a ideia de apoio se encontra paradoxalmente justaposta à de desvio. $O$ argumento principal que nos leva a destacar essa questão aponta precisamente para a singularidade da sexualidade humana, cuja meta se dirige à obtenção do prazer, e não à reprodução, tendo, portanto, como base a esfera do desejo. Em última instância, esse caminho é desviante em relação à meta essencial que define concretamente o sexual biológico, ancorado que este é, fundamentalmente, na esfera da necessidade, alimentado, em grande parte, pela força instintual. Quando a puberdade chega, o terreno psíquico já está ocupado pelas fantasias inconscientes próprias da sexualidade infantil. Ou seja, na sexualidade infantil, a presença de fantasias inconscientes precede o advento da puberdade. Sexualidade, aqui, deve ser entendida no sentido amplo de uma psicosexualidade.

A abertura à relação sexual propriamente dita é produtora de desequilíbrio no plano do conflito pulsional. Esse conflito, enquanto motor da vida psíquica, se apresenta de modo especialmente problemático por conta, por um lado, da intensificação do que concerne ao sexual e, por outro lado, pela fragilização e pelas transformações de ordem identitária promovidas, em larga escala, pelas exigências de ordem social (CARDOSO; MARTY, 2008).

As novas demandas ao sujeito na adolescência, características da vida adulta, com a exigência crescente de autonomia, de apropriação subjetiva, de afirmação identitária, de efetivação de escolhas dos mais diversos tipos, fazem com que as operações internas do psiquismo tenham de ser realizadas em outro patamar, profundamente diverso daquele travado no decorrer na vida infantil. Merece ser fortemente ressaltada neste ponto a questão das perdas e dos lutos inerentes à adolescência. De acordo, por exemplo, com Kernier (2015), a referência quanto a esse aspecto é, dentre outras, a perda do corpo infantil, dos pais próprios à infância, da proteção de natureza social, no sentido amplo do termo (referente ao laço social e suas condições, limites e possibilidades que faziam jus à criança), múltiplas e dolorosas perdas, necessitando, portanto, de intenso trabalho de luto para que possam ser elaboradas. De certo modo, em síntese, pode-se considerar a adolescência como uma experiência que envolve múltiplas perdas.

Não por acaso, é no decorrer desse processo que tantas situações clínicas, das mais leves às mais graves, encontram justamente seu desencadeamento. A adolescência é, de certo modo, uma situação fronteiriça que envolve violência psíquica, estando essa dimensão situada no limiar de diferentes graus de sofrimento e com distintos destinos na vida psíquica. 
Conceituar "adolescentes" e "adolescência" é motivo de muitas publicações e questionamentos, considerando os diferentes pontos de vista sob os quais essa etapa do desenvolvimento do ser humano tem sido estudada. O Fundo das Nações Unidas para a Infância (do inglês, United Nations Children's Fund - Unicef) e a Organização Mundial de Saúde (OMS) definem como adolescente a pessoa na segunda década de vida, ou seja, dos 10 aos 19 anos de idade. O Unicef considera útil a divisão entre a adolescência precoce, que vai dos 10 aos 14 anos, e a adolescência tardia, dos 15 aos 19 anos, dadas as diferenças marcantes de experiências e mudanças internas e externas entre essas fases (UNICEF, 2011). O Estatuto da Criança e do Adolescente (ECA) define a adolescência como a faixa etária que vai dos 12 aos 18 anos (BRASIL, 1990).

Segundo o Unicef (2011), definir a adolescência é complexo, tendo em vista que cada indivíduo experimenta essa fase de maneira única; a puberdade ocorre em idades diferentes entre meninos e meninas e pode acontecer antes da faixa etária prevista (especialmente para meninas); os marcos legais variam entre os países para definir a idade a partir da qual pode haver participação em atividades reservadas a adultos (votar, trabalhar, casar, exercer atividades militares, consumo de álcool) e nem sempre correspondem ao desenvolvimento da capacidade desses adolescentes para exercê-las; e, por fim, muitos adolescentes estão engajados nessas atividades, tendo suas adolescências "roubadas".

Corroborando com essa complexidade, há autores que defendem que a adolescência não deve ser vista apenas como um período natural do desenvolvimento e que, apesar de ser marcada por um corpo em desenvolvimento, elementos biológicos e fisiológicos não têm expressão direta na subjetividade, que é significada pela sociedade (OZELLA; AGUIAR, 2008). As condições sociais não apenas facilitam, contribuem ou dificultam o desenvolvimento de determinadas características do jovem, elas constroem uma determinada adolescência (AGUIAR; BOCK; OZELLA, 2001). Assim sendo, o melhor é considerarmos "adolescências" ao invés de "adolescência".

Ozella e Aguiar (2008), ao se depararem com a forma "naturalizante e aistórica" com que adolescente e adolescência são muitas vezes analisados e compreendidos, realizaram um estudo qualitativo com jovens de 14 a 21 anos em São Paulo para analisar a concepção de adolescência, o significado da passagem da adolescência para a vida adulta e as fontes que originaram a concepção de adolescência. Os resultados mostraram que, apesar de alguns aspectos em comum, há uma diversidade entre os adolescentes basicamente em função de classe social, gênero e etnia, aspectos que se mostraram determinantes na constituição da subjetividade e no lidar com a realidade social.

Se por um lado a adolescência é carregada de complexidade, no plano subjetivo, Bourdieu (1983) diria que "juventude é apenas uma palavra". Nessa medida, ser jovem é uma denominação atribuída numa perspectiva relacional: "Somos sempre o jovem ou o velho de alguém" (BOURDIEU, 1983, p. 114) e de acordo com critérios que são arbitrados culturalmente. Como acontece com os demais segmentos etários, a adolescência é sujeita a variações que podem antecipar, prolongar, encurtar ou suprimir essa fase da vida. Desse modo, é importante sinalizar que não é possível configurar apenas uma condição juvenil no Brasil, nem mesmo nos espaços urbanos.

A despeito de, no plano legal, os adolescentes serem considerados iguais, sem distinção de qualquer espécie, a dualidade entre adolescentes pobres e os demais pertencentes a outros estratos ainda se faz presente nas relações sociais. Por essa razão, o exame dessa dualidade é produtivo para analisar visões e práticas discricionárias. 
A inscrição de classe e de raça/cor traduzem-se em referências determinantes na vida dos indivíduos na medida que influenciam de modo direto as oportunidades de acesso e desfrute dos bens materiais e simbólicos que uma dada sociedade conquistou. Essas referências inauguram um processo de socialização que, embora não defina de maneira fatalista a trajetória dos indivíduos, posiciona-os diante do acesso à riqueza produzida, marcando o alcance desse acesso e os contornos de sua identidade juvenil (DUBAR, 1998). A origem social e racial dos adolescentes, parafraseando Durkheim [1985]/(2001)' quando conceitua o "fato social", são marcas externas que os antecedem na sua relação com o mundo e assumem uma superioridade sobre as demais dimensões e características que os singularizam.

Alguns dados acerca da população brasileira foram escolhidos e serão apresentados como forma de ilustrar as diferenças na origem e na trajetória dos jovens no Brasil. Comecemos pela desigualdade de renda. Segundo a Síntese de Indicadores Sociais, documento elaborado pelo Instituto Brasileiro de Geografia e Estatística (IBGE), em 2020, "o rendimento domiciliar per capita médio da população preta ou parda, ao longo do período compreendido entre 2012 e 2019, permaneceu cerca de metade do observado para a população branca" (IBGE, 2020, p. 55), correspondendo ao valor de $\mathrm{R} \$ 981$ para a população preta e parda e $\mathrm{R} \$ 1.948$ para a branca. Mesmo considerando que a renda não é o único critério para definir pobreza, essa diferença é ainda muito expressiva e favorece, de maneira escalar, outras formas de desigualdade.

Em termos das condições de moradia, os mais jovens estão mais expostos ao que o IBGE denomina de inadequações domiciliares, ou seja, os domicílios cujas condições indicam precariedade ou vulnerabilidade, representando restrições ao direito à moradia adequada e também a ausência de serviços de saneamento - resultado que se relaciona com a maior presença de crianças e jovens em domicílios com menores rendimentos (IBGE, 2020).

Os jovens que nem estudam, nem trabalham são contemporaneamente denominados "geração nem, nem". Embora essa geração compreenda todos os jovens nessa condição, adolescentes de origem pobre são os que mobilizam maior interesse por explicitarem uma condição que gera um sentimento de incômodo ou de ameaça. A educação é outra dimensão importante para caracterizar as desigualdades na origem e no percurso da vida. A escola, juntamente com a família e a comunidade constituem referências importantes para a socialização de crianças e adolescentes. No entanto, a escola nem sempre é considerada como um espaço de socialização, mas como uma instituição voltada para formação profissional, sendo a criança e o adolescente atores passivos de um projeto que se constitui, em muitos casos, sem considerar seus interesses e demandas. Para muitos segmentos da sociedade que não têm acesso às escolas com propostas político-pedagógicas críticas e criativas, o protagonismo infanto-juvenil é secundarizado ou mesmo inexistente. Também se observa que não há um reconhecimento da escola como lugar de trocas, de ampliação do capital cultural e de expressão de identidades e valores. Um provérbio largamente difundido afirma que "é preciso estudar para ser alguém na vida". Esse provérbio apresenta a escola como um espaço que permite a mobilidade social a partir do esforço individual. Ainda que adotemos uma concepção restrita de escola como espaço de formação profissional e de mudança do patamar de origem, é possível observar que essa função não está sendo exercida com sucesso.

1 A data entre colchetes indica o ano de publicação original da obra. Nas citações seguintes será registrada apenas a data da edição consultada pelas autoras. 
A relação entre raça/cor e renda no Brasil é reveladora da herança discricionária que afeta esse segmento. De acordo com dados em série histórica sobre ocupação, os negros, considerando todos os postos de trabalho, são pior remunerados do que os não negros (IBGE, 2020). A vulnerabilidade dos adolescentes negros se expressa não apenas nos indicadores de desemprego ou de não ocupação, mas na distribuição da população jovem por grupos de ocupação. A distribuição dos segmentos juvenis ocupados revela a presença mais expressiva de negros em frentes de trabalho que exigem menos escolaridade e/ou que representam menor status e ofertam menor remuneração.

Vincular o adolescente pobre ao mundo do trabalho tem se mostrado uma estratégia de intervenção muito empregada para atenuar o incômodo e a ameaça que sua condição social representa. Quando associado ao trabalho, o adolescente pobre mobiliza um julgamento moral em seu favor: o trabalhador é considerado um "pobre merecedor". A ideia de "deserving poor" tem origem na Inglaterra vitoriana inglesa e se aplicava àquele indivíduo reconhecido pelo esforço de se manter integrado à lógica produtiva, sendo, por isso, merecedor de credibilidade e de assistência (HIMMELFARB, 1988). Os demais, considerados pobres não merecedores, eram assim reputados pela falta de empenho ou por serem portadores de características consideradas nocivas ou desviantes, como o uso abusivo de drogas, a mendicância, a propensão à criminalidade, entre outros. Essas ideias, embora antigas, não foram totalmente superadas e continuaram sendo mobilizadas para segmentar os pobres, explicar sua condição e validar algumas propostas de intervenção, incluindo a negligência no atendimento.

Desde a década de 1990, devido a intensas campanhas que sucederam a promulgação do ECA, o trabalho infantil apresenta uma tendência decrescente. De fato, a Pesquisa Nacional por Amostras de Domicílios (PNAD) Contínua sobre Trabalho de Crianças e Adolescentes relativa ao ano de 2019, elaborada pelo IBGE, mostrou que o trabalho infantil no Brasil caiu de 5,3\%, em 2016, para 4,6\% das pessoas de 5 a 17 anos, em 2019 (IBGE, 2020). Apesar dessa diminuição, ainda havia 1,8 milhão de crianças e jovens nessa situação no país. Seus efeitos perversos foram largamente estudados e são considerados como a principal razão de evasão escolar e, consequentemente, de restrição para mobilidade social. Ainda assim, dadas as condições precárias de vida de muitas famílias brasileiras, observa-se um contingente expressivo de crianças e adolescentes que passam os dias nas ruas, desempenhando atividades como engraxates, vendedores ambulantes e outras ocupações no mercado informal para suprirem a renda familiar. Muitos adolescentes em condição de subemprego são considerados mais merecedores do que outros que circulam nas ruas em situação de mendicância ou sem ocupação. Isso indica que, embora o trabalho infantil seja legalmente considerado uma violação, sua representação social nem sempre coincide com a interpretação da lei.

Considerando a escolarização precária ou incompleta e, como consequência, a baixa qualificação para o mercado de trabalho, o cenário de oportunidades para um adolescente pobre é mais restrito e menos promissor. O recrutamento para atividades relacionadas ao tráfico de drogas ilícitas, por outro lado, aparece como uma alternativa de mobilidade social, de reconhecimento (ainda que imposto pelo medo) e de acesso a diversos recursos (materiais e simbólicos), que, na sua trajetória, se apresentaram escassos.

Tais inscrições sociais revelam a pobreza como uma marca naturalizada e apontam formas de negligência da sociedade e do Estado no enfrentamento das desigualdades e no provimento de suporte por meio de políticas redistributivas e protetivas. 
A questão da negligência, como uma das dimensões da violência, nos interroga sobre determinações de base que remetem a elementos intrapsíquicos e intersubjetivos, nos quais estão implicados fatores psíquicos, sociais, biológicos, culturais. Vamos nos ater, primeiramente, em alguns elementos psíquicos implicados na articulação violência/ negligência, tendo em vista a singularidade da experiência subjetiva da adolescência.

Um dos aspectos a serem destacados diz respeito à negligência do outro, mas, igualmente, à violência contra si mesmo, seja pela via do ato, seja pela via da paralisação da existência, da recusa ao agir. Mesmo na negligência dirigida, em última instância, contra si mesmo, as determinações são múltiplas, envolvendo a relação com a alteridade e sempre tendo o contexto sociocultural como solo do processo de formação e de funcionamento psíquicos. A questão do ambiente na constituição subjetiva não se limita à qualidade do encontro com o outro primordial, com o cuidador, com aquele que ampara biológica e afetivamente, introduzindo o indivíduo num universo subjetivo, pulsional. $\mathrm{Na}$ mesma linha de importância, conforme desenvolve Furtos (2012), trata-se de um encontro com os objetos sociais.

$\mathrm{Na}$ adolescência dá-se um violento confronto com o "estranho" pelo advento do novo, mas, ao mesmo tempo, há a insistência do familiar, desde o mais arcaico, o primário, até um registro secundário, a partir de então, em estágio de ressignificação, movendo e remanejando profundamente diferentes camadas no espaço psíquico. No que concerne à dimensão do tempo, outro elemento muito relevante na adolescência e interligado com a questão da violência e da negligência, há o confronto implicado na diferença geracional. Não é somente a diferença sexual que se coloca em jogo em novo e crítico patamar, ou a diferença de gênero ou, mais amplamente, o problema da escolha de objeto sexual. A crise da adolescência corresponde à crise da idade madura nos pais, em seu psiquismo e na revivência de toda sua história psíquica pregressa.

A experiência subjetiva da adolescência corresponde ao confronto com o processo de envelhecimento das figuras parentais, implicando, de forma diferente, mas não menos intensa ou traumática, a perda de sua juventude, tendo em vista os destinos dessa experiência em seu próprio psiquismo. Impõe-se também, para eles, violenta perda de sua condição, quase onipotente de protetores de seus filhos.

Quando há revivência de vividos mal elaborados, impeditivos de adequado e elaborado luto, o descolamento das figuras parentais, particularmente de sua representação no mundo interno não se efetivar, a presença desses objetos tende a insistir, numa verdadeira ocupação no mundo interno, sem se deixar apagar (KERNIER, 2015). O eu precisa se fazer seu, identificar-se, consolidar o processo identificatório, o que adveio do outro, desde os primórdios da vida e no decorrer de diferentes experiências internas e externas até a adolescência, delimitando seu território próprio interno, suficientemente separado dos objetos parentais, primordiais, para se consolidar o "sentimento de continuidade de si” (Winnicott, 1975). Para tal, mostra Freud (1940/1969, p.237), inspirado por célebre frase de Goethe ${ }^{2}$ que aquilo que foi herdado dos pais precisa ser conquistado. A travessia da adolescência é fundamental nesse processo de apropriação e de consolidação identitária.

2 “Aquilo que herdaste de teus ancestrais, conquísta-o para fazê-lo teu”" (Goethe, Fausto, Parte I, Cena I, 2013). 
Mas pode haver excessiva e traumática insistência do que concerne ao vínculo com as figuras parentais, entravando o trabalho de luto, que implicaria uma elaboração das perdas resultantes desse necessário processo de separação. Na impossibilidade disso, a violência psíquica que implica a adolescência não comporta mais caráter estrutural, inerente a ela. Nesse caso, estamos diante de uma situação traumática, e as respostas psíquicas defensivas podem ser extremas, tais como as passagens ao ato, à inação. Nesse conjunto, ressaltam vários autores, dentre eles vale mencionar a contribuição de Marty e Larue (2012), estão as respostas de tipo precário, sem elaboração suficiente quanto à qualidade do trabalho psíquico demandado.

Nas patologias limites, nas situações fronteiriças, de sofrimento identitário-narcísico (ROUSSILLON, 1999), como, por exemplo, nas situações clínicas que envolvem dependência extrema do objeto, naquelas em que impera a agressividade dirigida ao outro ou a si mesmo, nas graves depressões, nas passagens ao ato, inações e nos prolongamentos extremos da adolescência, há um movimento que pode ser considerado enquanto negligência de si mesmo, como quebra extrema no cuidado de si. Porém, essa negligência, essa violência exercida contra si mesmo, pela falta de esperança ou pelo seu oposto, o desespero do imediatismo, a história psíquica de cada sujeito, em sua singularidade - e que se entrecruza necessariamente com a do contexto sociocultural no qual emergiu e vive - nos obriga a analisar o universo relacional, a questão das fronteiras entre o eu e o outro, tendo em vista não somente a qualidade do investimento do outro externo, mas, fundamentalmente, a forma como foram processadas essas relações.

O encontro com a alteridade é elemento essencial do ponto de vista intrapsíquico e intersubjetivo. A qualidade desse encontro deve ser necessariamente considerada na análise teórica e clínica da problemática da violência e da negligência. É na relação eu/ outro que podemos situá-la, a alteridade aí envolvida remetendo a múltiplos registros, internos e externos, com toda a complexidade que comporta. Nela se articulam o plano biológico, psíquico, social, cultural através dos quais e por meio de seu profundo entrelaçamento se trava essa relação, no interior da qual a dimensão do cuidado, correlativa à de negligência, pode ser pensada. Exploremos, a seguir, outros importantes ângulos dessas questões.

As diretrizes nacionais para a atenção integral à saúde de adolescentes e jovens enfatizam a importância de fortes laços intersetoriais (saúde, outros setores e comunidades) para a produção de saúde para essa faixa da população e propõem uma reflexão sobre a necessidade de um modelo de atenção à saúde integrado interfederativamente e que responda às especificidades de cada região do país (BRASIL, 2010). As diretrizes chamam atenção, ainda, para o conceito ampliado de saúde, em suas diversas dimensões, e os múltiplos fatores (ambientais, sociais e culturais) que afetam a saúde de adolescentes e jovens.

Há décadas a violência é internacionalmente reconhecida como causadora de consequências adversas para a saúde, a educação e o comportamento de crianças e adolescentes. Abusos sexual, físico e emocional, negligência e exposição à violência doméstica causam problemas de forma direta e indireta nos envolvidos. Todavia, poucos são os estudos de prevalência com abrangência nacional da violência e os existentes são muito variáveis quanto a metodologias, definição de violência, tipos de violência incluídos, fontes de dados, dentre outras diferenças, o que dificulta a comparação entre os países, a compreensão do problema de forma global e as propostas de ação para lidar com a situação (MATHEWS et al., 2020). 
Recentemente, Pereira et al. (2020) publicaram dados sobre violências (interpessoais ou autoprovocadas) contra adolescentes (10 a 19 anos) no Brasil, tendo como base notificações feitas pelo setor saúde ao Sistema de Informação de Agravos de Notificação (Sinan) entre 2011 e 2017, procedentes de 75,4\% dos municípios brasileiros. Os tipos de violência mais notificados foram: física (64,7\%), sexual (24,7\%), psicológica (24,5\%) e negligência/abandono (12,2\%). Violência sexual e psicológica tiveram maior frequência entre as mulheres, enquanto violência física e negligência/abandono foram mais frequentes entre os homens. As lesões autoprovocadas corresponderam a $18,5 \%$ das notificações e ocorreram em maior proporção entre mulheres.

Considerando o recorte do nosso artigo, ressaltamos que no estudo supracitado a negligência predominou no grupo com idade de 10 a 14 anos, quando perpetrada de forma repetitiva, no domicílio, praticada por familiares. Ela foi significativamente inferior no sexo feminino, na raça/cor negra, amarela, indígena e quando havia suspeita de ingestão de bebida alcoólica pelo agressor (PEREIRA et al., 2020).

Entretanto, quando os dados divulgados têm como origem os serviços de proteção, internacionalmente a negligência é o tipo de violência mais frequente. Nos Estados Unidos, $75,4 \%$ das crianças que receberam proteção em 2015 estavam em situação de negligência. Foi também mais frequente (61\%) dentre as formas de maus-tratos em geral encontradas pelo National Incidence Studies (NIS), agência destinada a estimar a incidência de maus-tratos com ou sem envolvimento com serviços de proteção (TURNER et al., 2019).

Da mesma forma, no Brasil, os dados provenientes dos conselhos tutelares ou do disque 100, diferentemente das estatísticas geradas pelas notificações dos serviços de saúde ao Sinan, mostram a negligência familiar como o tipo de maus-tratos mais frequente. No banco de dados do Sistema de Informação para a Infância e Adolescência Módulo Conselho Tutelar (SIPIA-CT), que compila as notificações colhidas pelos conselhos tutelares com acesso ao sistema no Brasil, as referências a um conteúdo análogo à negligência estão presentes em todas as formas de violação, embora o termo literal só figure quando referido ao ambiente familiar. São exemplos de referências análogas: atendimento inadequado, prejuízo à vida por ação ou omissão, discriminação, atos atentatórios à cidadania, negação do direito, falta de condições ou condições irregulares para acesso a direitos (BRASIL, 2003).

Os dados provenientes dos serviços de proteção geram uma visão limitada do problema da negligência, pois tendem a representar apenas a parcela de casos mais graves, que geraram algum dano "visível" à criança ou ao adolescente. Outro aspecto presente nas formas de notificação é a atribuição de um responsável direto pela violação. A tendência mais frequente é a de atribuir a quem tem a função tradicional do cuidado a maior responsabilidade na proteção. $O$ cometimento de atos infracionais por adolescentes tende a ser explicado pela negligência da mãe na supervisão e na transmissão de bons valores. No documento "The state of the world's children: adolescence an age of opportunity", o Unicef (2011) chama atenção para o quanto os adolescentes (e suas diferentes vivências de adolescência) estão negligenciados, para a necessidade de proteção e de investimento em ações que podem ser desenvolvidas para seu bem-estar em diferentes partes do mundo. 
Pereira et al. (2020, p. 11) ressaltam, em relação à negligência, que:

\begin{abstract}
Esse tipo de violência é de difícil definição e necessita de elementos fundamentais para identificação, como os contextos de pobreza, isolamento, privação social e outras carências presentes na história de vida dos pais e das vítimas. Esses fatores, relacionados à violência estrutural perpetrada historicamente contra milhões de famílias brasileiras, dificultam julgamento mais preciso entre a prática abusiva e a impossibilidade de prover os requisitos para o desenvolvimento de crianças e adolescentes.
\end{abstract}

Enquanto os demais tipos de maus-tratos ocorrem por ações, a negligência decorre de atos de omissão, difíceis de especificar e mensurar, sendo habitualmente classificada em três grandes grupos: física, de supervisão e emocional.

Turner et al. (2019) estudaram a relação entre indicadores socioeconômicos e as negligências física e de supervisão. O estudo envolveu 3.581 crianças (de 2 a 9 anos) e 4.271 adolescentes (10 a 17 anos), concluindo que a negligência física está diretamente vinculada a estressores econômicos, enquanto a educação dos pais é determinante tanto para negligência física quanto de supervisão. Considerando que esses indicadores socioeconômicos não foram igualmente importantes para o risco de outras formas de maus-tratos, os autores sugerem que políticas e intervenções que visem reduzir as adversidades econômicas e melhorar a compreensão dos pais sobre as necessidades das crianças podem reduzir a negligência. Ressaltam também a importância de avaliar se essas crianças e adolescentes estão sofrendo outras formas de vitimização, dentro e fora do ambiente familiar, considerando que frequentemente a negligência é apenas uma dentre uma gama de vitimizações que esses sujeitos vivenciam. Os autores concluem ser particularmente importante identificar a polivitimização dentre os que estão em situação de negligência. Ao identificar outras formas de vitimização - e não apenas outras formas de maus-tratos - e contextos que expõem crianças e adolescentes a maior risco, aumentam as chances de as intervenções planejadas serem mais eficazes.

\title{
Um convite à reflexão sobre uma situação de negligência
}

Encerrando este artigo, apresentamos uma situação fictícia como um convite ao leitor para refletir a respeito do que foi discutido anteriormente.

Aline, uma mulher negra de 15 anos, comparece à consulta na Clínica da Família com seu filho de 1 mês de idade. Começou o pré-natal no último trimestre de gestação, quando foi detectado que estava com sífilis. A gestação não foi planejada, mas Aline ficou feliz com a gravidez. A adolescente mora com sua mãe, de 30 anos, que aceitou sua condição. Ela e o bebê fizeram o tratamento proposto pela equipe de saúde, mas o pai da criança se recusou a fazer os exames e, portanto, não se sabe se ele está com sífilis. Aline e o pai do bebê (16 anos) não moram juntos e ele não quer registrar a criança em seu nome, apesar de manter relacionamento com Aline até o momento. Ele estuda e sua família não tem condições de ajudar financeiramente. A mãe de Aline trabalha fora o dia todo e, portanto, não tem condições de ajudá-la nos cuidados com o bebê. Por não ter com quem deixar a criança, Aline parou de frequentar a escola e, como os gastos aumentaram, tem ido vender doces no sinal ou no trem, levando consigo o bebê, que está em fase de aleitamento materno exclusivo. A médica que atendeu Aline identificou que tanto ela quanto o bebê encontram-se em situação de risco social e de saúde. 
Observa-se, nesse caso, vários aspectos que envolvem a ausência de cuidado e autocuidado e revelam formas de negligência com origens, durações e implicações distintas. Do ponto de vista estrutural, o Estado brasileiro se mostra negligente ao não viabilizar direitos sociais de modo universal e seletivamente não priorizar essa fase da vida, a despeito de o ECA assim prescrever em seu artigo $4^{\circ}$ (BRASIL, 1990).

A origem de classe, de raça e gênero dessa adolescente posicionam-na de modo muito desfavorável diante das oportunidades de acesso a bens e serviços. Os indicadores sociais anteriormente referidos indicam a invisibilidade ou a visibilidade perversa que o segmento ao qual ela pertence representa diante dos dados de escolaridade, ocupação, moradia, saúde e outros que expressam direitos previstos pelo ECA.

Quando omissas ou inefetivas nas atribuições que lhe competem, as diversas instituições que compõem o Estado tendem a delegar aos familiares e aos próprios adolescentes $\mathrm{o}$ atendimento às demandas que também lhe competem. Essa delegação se mostra ainda mais justificada quando motivada por uma alegada "razão comportamental": gravidez na adolescência, evasão escolar, uso abusivo de drogas, entre outras. No caso de Aline, engravidar e deixar a escola pode ser entendido como uma escolha individual com consequências danosas. A responsabilização individual desfoca a relação dessa adolescente do seu contexto sociocultural e não considera suas escolhas individuais como expressões do seu tempo e das relações sociais mais amplas. A omissão ou ineficiência do Estado não aparece no questionamento sobre suas condições habitacionais, sobre os recursos que seu território dispõe, sobre como a temática da sexualidade e do cuidado com o corpo foi apresentada nas escolas e nas unidades de atenção básica. A passagem da "batata-quente" para a família se traduz numa forma de contenção e de desresponsabilização do Estado, mesmo que a família se encontre desprotegida e, portanto, sem condições de proteger.

A saúde de Aline é outro aspecto que merece atenção. Gravidez na adolescência é um evento de risco para mãe e bebê. Além dos riscos sociais já citados, pode haver ainda anemia, hipertensão arterial grave, mortalidade materna, depressão pós-parto, prematuridade, dentre outros problemas (SOCIEDADE BRASILEIRA DE PEDIATRIA, 2019). Quando acompanhada de uma infecção sexualmente transmissível (IST), como no caso, esse risco é ainda maior, haja vista que a IST aumenta o risco de abortamento, a criança pode nascer contaminada e ter sequelas decorrentes da doença e a exposição a um tipo de IST aumenta a suscetibilidade a associações com outras IST (NERY et al., 2015).

Não é raro que os parceiros não aceitem fazer a investigação para IST, o que demanda dos serviços de saúde um planejamento singular para cada situação, com busca ativa do parceiro, a fim de compreender os vínculos afetivos existentes, de proporcionar o cuidado adequado à situação e a proteção dos envolvidos (pai, mãe e bebê).

Sexualidade, métodos contraceptivos, planejamento da gravidez e prevenção de IST são temas que precisam ser incluídos no dia a dia dos adolescentes. Laços familiares fortalecidos, rede de apoio próxima e atuante, conversas no ambiente escolar ou nos serviços de saúde podem proporcionar espaços "terapêuticos" e de troca de informações sobre esses temas fundamentais aos adolescentes. No caso de Aline, prevenir IST e outra gravidez em curto prazo, proporcionar a volta à escola e providenciar vaga em creche para seu bebê são ações de proteção que não devem ser negligenciadas, pois são fatores determinantes para sua saúde e inserção na sociedade.

O que foi observado a respeito das dimensões social e de saúde implicadas no caso nos faz pensar no caráter indissociável entre universo psíquico e universo sociocultural. 
Os importantes elementos de natureza psíquica, conscientes e inconscientes, implicados nesse caso se entrecruzam com aqueles que concernem a um contexto determinado. O ambiente desempenha papel fundamental desde o início da vida de cada indivíduo e a noção de ambiente não se limita aos cuidados do outro imediato, ou seja, exercido por aqueles que desempenham a função materna e paterna. É preciso ter em conta o aspecto fundamental de outra camada, constituída justamente por objetos sociais vinculados à qualidade no plano do laço social no interior do qual a experiência subjetiva se forma e transcorre.

Como tópico de especial relevo, do ponto de vista psicanalítico, vale sublinhar a situação da gravidez em sua ressonância psíquica. Quais seriam os elementos vinculados aos desejos, às fantasias infantis que fazem parte da história subjetiva dessa jovem, que teriam levado-a, no que tange aos fatores de natureza psíquica, a engravidar tão cedo? Uma multiplicidade de fatores certamente esteve em jogo trazendo à cena sua história singular de vida, devendo-se levar em conta não somente os vividos atuais, mas também o que houve de determinante na sua infância.

A existência de certa quebra da proteção de si mesma, da negligência do cuidado de si, tendo em vista a precoce exposição a uma vivência tão crucial e complexa como a maternidade, comporta em si mesma a esfera corporal, já que se trata de um ato no qual a capacidade psíquica de mediação, do psiquismo poder dar conta do turbilhão interno que está em curso, parece apresentar falhas significativas. A questão que se coloca é se essa atuação não seria reveladora de precariedade da utilização dos recursos psíquicos diante das dificuldades colocadas pela experiência da própria adolescência.

No caso em questão, a falta de proteção, de confiança no amparo de um ambiente mais amplo, social, relativa aos objetos sociais, parece ter desempenhado forte papel nessa situação, em que vem abruptamente a se tornar cuidadora, agora como mãe. Poderia haver nessa passagem, em algum plano, a tentativa de conquistar uma posição subjetiva afirmativa. Mas, ao se tornar mãe nessas circunstâncias, a jovem paradoxalmente vem a se fixar numa posição de dependência. A relação mãe/filha, própria à vida infantil violentamente, se pereniza - negligência de si mesma, da sua possibilidade de seu efetivo crescimento como sujeito, negligência do outro, enquanto ameaça potencial de precariedade a que a nova criança possa ser exposta. Estamos, assim, diante de significativos entraves no trabalho de luto que o adolescente deverá necessariamente fazer, tarefa nada simples, e que se realiza num espaço, relacional, no âmbito do mundo interno, do ambiente familiar e na inserção social.

Ao apresentarmos a negligência como uma manifestação de violência nem sempre visível e enfrentada na adolescência, consideramos sua ocorrência como um processo, e não como uma circunstância episódica. As elaborações subjetivas, assim como as determinações sociais, são necessárias ao seu reconhecimento e superação. As reflexões apresentadas apontam para a complexidade da prevenção e da intervenção em situações de negligência às quais muitos adolescentes estão submetidos no nosso país, sendo necessárias análises situacionais e a implementação de ações com olhares simultâneos de diversos campos do saber. 
AGUIAR, W. M. J.; BOCK, A. M. B.; OZELLA, S. Orientação profissional com adolescentes: um exemplo de prática na abordagem sócio-histórica. In: BOCK, A. M. B.; GONÇALVES, M. G. M.; FURTADO, O. (Org.). Psicologia sócio-histórica: uma perspectiva crítica em psicologia. São Paulo: Cortez, 2001. p.163-178.

BOURDIEU, P. A “juventude" é apenas uma palavra. In: BOURDIEU, P. Questões de Sociologia. Rio de Janeiro: Marco Zero, 1983. p. 112- 121.

BRASIL. Estatuto da Criança e do Adolescente. Lei no 8.069, de 13 de julho de 1990. Dispõe sobre o Estatuto da Criança e Adolescente e dá outras providências. Brasília, 1990.

- Sistema de informação para infância e adolescência: SIPIA. Brasília: Secretaria Nacional de Promoção dos Direitos da Criança e do Adolescente, 2003.

. Diretrizes nacionais para a atenção integral à saúde de adolescentes e jovens na promoção, proteção e recuperação da saúde. Brasília: Ministério da Saúde, 2010.

CARDOSO, M.; MARTY, F. (Org.). Destinos da adolescência. Rio de Janeiro: 7Letras/ Faperj, 2008.

DUBAR, C. Trajetórias sociais e formas identitárias: alguns esclarecimentos conceituais e metodológicos. Educação e Sociedade, Campinas, v. 19, n. 62, abr. 1998.

DURKHEIM, É. As regras do método sociológico. 8. ed. Lisboa: Editorial Presença, 2001.

FREUD, S. Esboço de Psicanálise (1940). In: FREUD, S. Edição Standard Brasileira das Obras Psicológicas Completas de Sigmund Freud. Rio de Janeiro: Imago, 1969. Vol. XXIII, p. 165-237.

FURTOS, J. La clinique psychosociale et la souffrance d'exclusion comme paradigmes des situations extrêmes. In: MARTY, F.; ESTELLO, V. (Org.). Cliniques de l'extrême. Paris: Armand Colin, 2012. p. 265-288.

GOETHE, J. W. Fausto. Lisboa: Relógio D’agua, 2013.

HIMMELFARB, G. La idea de la pobreza: Inglaterra a principios de la época industrial. México: Fondo de Cultura Económica, 1988.

IBGE. Síntese de indicadores sociais: uma análise das condições de vida da população brasileira - 2020. Rio de Janeiro: IBGE, 2020.

KERNIER, N. 30 grandes notions de psychopathologie de l'enfant et de l'adolescent. Paris: Dunod, 2015.

LAPLANCHE, J. Pulsão e instinto: oposição, apoios e entrelaçamentos. In: CARDOSO, M. R. (Org.). Adolescência: reflexões psicanalíticas. Rio de Janeiro: Nau editora/Faperj, 2001. p.13-28.

MARTY, F.; LARUE, M. Extrêmes de la violence à l'adolescence. In: MARTY, F.; ESTELLON, V. (Org.). Cliniques de l'extrême. Paris: Armand Colin, 2012. p. 25-38.

MATHEWS, B. et al. Improving measurement of child abuse and neglect: a systematic review and analysis of national prevalence studies. PLoS ONE, San Francisco, v. 15, n. 1, jan. 2020. https://doi.org/10.1371/journal.pone.0227884.

NERY, J. A. C. et al. Infecções sexualmente transmissíveis na adolescência. Residência Pediátrica, Rio de Janeiro, v. 5, n. 3, p. 64-78, 2015. 
OZELLA, S.; AGUIAR, W. M. J. Desmistificando a concepção de adolescência. Cadernos de Pesquisa, v. 38, n. 133, p. 97-125, 2008.

PEREIRA, V. O. M. et al. Violências contra adolescentes: análise das notificações realizadas no setor saúde, Brasil, 2011-2017. Revista Brasileira de Epidemiologia, São Paulo, v. 23, suplemento 1, 2020. https://doi.org/10.1590/1980-549720200004.supl.1.

ROUSSILLON, R. Agonie, clivage et symbolisation. Paris: PUF, 1999.

SOCIEDADE BRASILEIRA DE PEDIATRIA. Prevenção da gravidez na adolescência. Guia Prático de Atualização. Departamento Científico de Adolescência/Sociedade Brasileira de Pediatria, 2019. Disponível em: <https://www.sbp.com.br/fileadmin/user_upload/ Adolescencia_-_21621c-GPA_-_Prevencao_Gravidez_Adolescencia.pdf $>$. Acesso em: 12 out. 2021.

TURNER, H. A. et al. Child neglect and the broader context of child victimization. Child Maltreatment, Washington, v. 24, n. 3, p. 265-274, 2019.

UNICEF. The state of the world's children: adolescence an age of opportunity. New York: Unicef, 2011. Disponível em: <https://www.unicef.org/sowc2011/>. Acesso em: 8 jun. 2021.

WINNICOTT, D. W. O brincar e a realidade. Rio de Janeiro: Imago, 1975.

RESUMO

Palavras-chave:

RESUMEN

Palabras clave:
Neste artigo, a adolescência é apresentada a partir de múltiplas dimensões que a caracterizam, fundamentada por formulações de distintos, porém complementares, campos disciplinares sobre essa experiência de vida. A proteção do adolescente é considerada uma atribuição coletiva, incluindo, além da autoproteção, um amplo conjunto relacional e institucional com seus recursos diferenciados, necessários e desejáveis para o asseguramento da qualidade de vida. Tendo como foco a negligência, em suas diferentes figuras, a adolescência é explorada em sua dimensão relacional, segundo a perspectiva de três áreas: a Medicina, o Serviço Social e a Psicanálise. 0 artigo é finalizado com um relato de atendimento produzido pelas autoras inspirado em demandas cotidianas de uma unidade de saúde, envolvendo uma adolescente em situação marcada por formas distintas de negligência, reflexão na qual se evidencia a riqueza de uma análise interdisciplinar acerca das temáticas exploradas.

violência, negligência, adolescente, trauma, fatores de risco.

\section{La adolescencia negligenciada: múltiples miradas}

En este artículo se presenta la adolescencia desde las múltiples dimensiones que la caracterizan, a partir de formulaciones de campos disciplinares diferentes pero complementarios sobre esta experiencia de vida. La protección del adolescente se considera una atribución colectiva, que incluye, además de la autoprotección, un amplio conjunto relacional e institucional con sus recursos diferenciados, necesarios y deseables para asegurar la calidad de vida. Teniendo como foco la negligencia en sus diferentes figuras, la adolescencia es explorada en su dimensión relacional, según la perspectiva de tres áreas: la Medicina, el Servicio social y el Psicoanálisis. El artículo termina con el relato de un atendimiento realizado por las autoras, inspirado en demandas cotidianas de una unidad de salud, envolviendo una adolescente en situación marcada por formas distintas de negligencia, reflexión en la cual es evidenciada la riqueza de un análisis interdisciplinar acerca de las temáticas exploradas.

violencia, negligencia, adolescente, trauma, factores de riesgo. 


\section{Neglected adolescence: multiple views}

ABStRACT

In this article, adolescence is presented from the multiple dimensions that characterize it, based on formulations from different but complementary disciplinary fields on this life experience. Adolescent protection is considered a collective attribution, including, in addition to self-protection, a broad relational and institutional set with its differentiated, necessary and desirable resources to ensure quality of life. Focusing on neglect, in its different figures, adolescence is explored in its relational dimension, according to the perspective of three areas: medicine, social work and psychoanalysis. The article ends with a report produced by the authors, inspired by the daily demands of a health unit, involving an adolescent subjected to different forms of neglect, a reflection in which the richness of an interdisciplinary analysis on the themes explored is highlighted.

Keywords: $\quad$ violence, neglect, adolescent, trauma, risk factors.

DATA DE RECEBIMENTO: 19/07/2021

DATA DE APROVAÇÃO: 12/10/2021

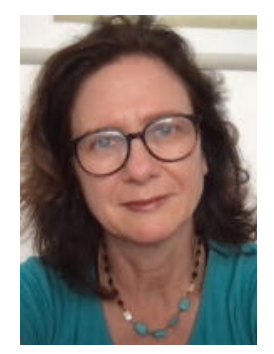

Joana Garcia

Universidade Federal do Rio de Janeiro, Escola de Serviço Social, Rio de Janeiro, Brasil. Assistente Social. Doutora em Serviço Social. Professora titular da Escola de Serviço Social/UFRJ, Brasil. Coordenadora do Núcleo de Estudos e Trabalho sobre Infância, Juventude e Famílias (NETIJ). Associada ao Centro de Defesa dos Direitos da Criança e do Adolescente (CEDECA-RJ).

E-mail: joanagarcia@ess.ufrj.br

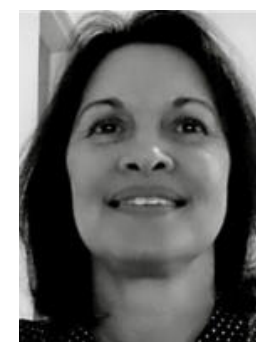

\section{Ana Lucia Ferreira}

Departamento de Pediatria da Faculdade de Medicina da Universidade Federal do Rio de Janeiro, Brasil. Médica pediatra. Doutora em Ciências pela Escola Nacional de Saúde Pública (ENSP)/Fiocruz. Professora Associada do Departamento de Pediatria da Faculdade de Medicina da UFRJ, Brasil.

E-mail: analuferr@gmail.com

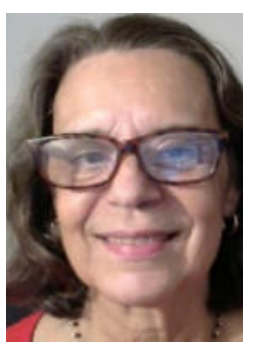

\section{Marta Rezende Cardoso}

Universidade Federal do Rio de Janeiro, Brasil. Instituto de Psicologia Departamento de Psicologia Clínica e Programa de Pós-Graduação em Teoria Psicanalítica. Psicóloga; Psicanalista; Doutora em Psicanálise e Psicopatologia Fundamental pela Université Paris Diderot, França; Professora Titular da UniversidadeFederal do Rio de Janeiro, Brasil; Pesquisadora do CNPq.

E-mail: rezendecardoso@gmail.com 